Original Article (short paper)

\title{
COVID-19 and Brazilian handball coaches: impacts on training prescription and professional learning
}

\author{
Vinicius da Silva Musa ${ }^{1}$ (D), Walmir Romário dos $\operatorname{Santos}^{1}$ (1) , Rodolfo Pombo Menezes² (D) , Valter Costa ${ }^{3}$ (D) , \\ Rodrigo Aquino ${ }^{4}$ (i) , Rafael Pombo Menezes ${ }^{1}$ \\ ${ }^{1}$ Universidade de São Paulo, Escola de Educação Física e Esporte de Ribeirão Preto, Ribeirão \\ Preto, São Paulo, Brasil; ${ }^{2}$ Universidade Federal Fluminense, Volta Redonda, Rio de Janeiro, \\ Brasil; ${ }^{3}$ Esporte Clube Pinheiros, São Paulo, São Paulo, Brasil, ${ }^{4}$ Universidade Federal do Espirito \\ Santo, Centro de Educação Física e Esportes, Departamento de Esportes, Vitória, Espírito Santo, Brasil. \\ Associate Editor: Ricardo Augusto Barbieri. Estácio UniSEB, Ribeirão Preto, SP, Brasil.
}

\begin{abstract}
This study aimed to analyze the influences of social isolation on the professional performance of Brazilian handball coaches and their expectations for the return of training sessions. Methods: Fifty-two handball coaches participated in this study $\left(\mathrm{M}_{\text {age }}=37.4\right.$ years; $\left.\mathrm{SD}_{\text {age }}=8.4\right)$, who coach $\mathrm{U}-8$ to adult teams, and answered an online survey divided into two main sections: a) coaches' actions with athletes and/or teams throughout social isolation; b) professional learning during social isolation. Descriptive statistics were used for quantitative data analysis and Thematic Analysis for qualitative data analysis. Results: The coaches mentioned that the contact with the teams has been made mostly with WhatsApp (94.2\%) and Google Meet or Zoom (75.0\%), in which coaches mainly emphasize physical fitness (69.2\%) and tactical knowledge (67.3\%). For professional learning, coaches are participating in online lectures $(96.2 \%)$, and virtual meetings $(92.3 \%)$. Coaches also seek content mainly related to teaching approaches $(82.7 \%)$, and specific handball exercises $(75.0 \%)$. Regarding expectations after the social isolation, coaches reported concern about uncertainties for sports practice (restriction of physical contact, decreased incentives for teams, and competitions) and possible psychological benefits (motivation to practice, overcoming difficulties, and learning new resources). Conclusion: The coaches revealed the concern about maintaining the athletes' performance during the social isolation, the uncertainties for the future of the teams, and the difficulties to use different resources for training. We suggested that the courses for coaches emphasize aspects that enable the learning of new technologies (e.g. social networks, video edition, and research platforms).
\end{abstract}

Keywords: SARS-CoV-2; social isolation; sports coaching; sports science.

\section{Introduction}

Since December 2019, humanity has experienced a time of crisis and challenges caused by the emergence of a new virus (SARSCoV-2 $)^{1,2}$. The rapid proliferation of the disease caused by this new virus (COVID-19) in humans and the lack of knowledge about drug treatments led the World Health Organization to declare a Public Health Emergency of International Importance 3 . While there has been no discovery of an efficient treatment for the disease, some measures are being taken to prevent exacerbated contagion and the collapse of public health systems ${ }^{1,2}$, such as closing borders, closing schools and universities, and canceling mass events $s^{4}$. Other measures have been encouraged, such as making people aware of their hygiene, social distance, and social isolation ${ }^{2}$.

In Brazil, the first registered case of COVID-19 was in February. In May (the month that this study took place) the country had more than 500.000 confirmed cases and almost 30.000 deaths $^{5}$, and on July 12th Brazil reported 1.800.827 cases $^{6}$. These data showed an increase in the number of infected people, which led states and cities to adopt social isolation as the main measure to face the COVID-19 dissemination since March of $2020^{7}$. Based on the assumption that its dissemination is associated with changes in average mobility ${ }^{8}$, universities, schools, gyms, bars, and restaurants were closed immediately, as well as sports activities and championships in progress were suspended. Despite the benefits of these measures, it has been affecting the daily life of the population and even causing social and psychological impacts ${ }^{2,9}$, as well as the possible emotional implications caused by other types of disasters, in which physical education classes can integrate various somatic and psychological stress relief strategies ${ }^{10}$.

Interviews with people in social isolation reported that one of the difficulties in this period is the maintenance of their jobs ${ }^{2}$, leading to the search for alternatives to recover or keep their jobs, and one of the means used is technological resources?. Physical Education teachers are also finding difficulties in social isolation, especially due to the importance of their interactions with students ${ }^{9}$ and the athletes with coach ${ }^{11}$ for the improvement of the athletes' performance ${ }^{12}$. 
In this sense, the restrictions imposed by the period of social isolation (preventing players from physically meet each other) have been demanding adjustments in relations with athletes and the professional learning of coaches. In this period, the time expended in a virtual environment for different tasks by coaches has increased such as maintaining relationships and practicing sessions with athletes, seeking specific content (for professional learning), and engaging in groups with their peers ${ }^{13}$.

As for training sessions during the pandemic, exercises that emphasize sports technique and physical conditioning have been used in this period due to the possibility of individualized execution and the need for few materials ${ }^{14,15}$. However, individual training at home can reduce specific exercise choices in a team sports context and does not provide teaching through games in a context with an internal logic similar to the full game, which can stimulate the essential interactions between teammates and opponents in a team sport and aims the game situations understanding ${ }^{16,17}$. Therefore, the analysis of the coaches' interventions is an important object of study for Sport Pedagogy, as it reveals the main alternatives to address the specific contents, the main barriers, and opportunities during the period of social isolation.

The current context of the COVID-19 pandemic allows the use of part of the time at home for professional learning and for activities that would not normally be performed, such as staying with the family ${ }^{2}$, even mentioning the difficulties to handle the technological resources to study ${ }^{18}$. In this sense, aspects related to professional learning by coaches also present emerging issues, especially within the Brazilian context. In Brazil, handball is organized by the Brazilian Handball Confederation ( $\mathrm{CBHb}$ ) and in each of the 27 federative units by their respective federations (directly linked to $\mathrm{CBHb}$ ), which promote handball mainly through the organization of competitions. Regionally, there are handball leagues independent of the federations, which also promote competitions at lower costs, especially for covering smaller regions (with cities closer together). Unfortunately, there is little participation of the entities mentioned above in the professional learning of coaches, which makes it important to identify and analyze the main content sought by coaches for their professional learning and to increase the performance of their teams.

Previous studies have shown that the opportunities they had to improve professional knowledge are decontextualized, punctual, do not meet coaches' expectations, and are far from their professional demands ${ }^{19}$. In addition, there is no representative entity organized by coaches at the national level that defends their interests and presents proposals for professional learning. This context leads handball coaches to seek individual alternatives for professional learning, especially in non-mediated situations $\mathrm{s}^{20}$. Therefore, identifying and discussing alternatives for professional learning (technologies and content accessed) during the pandemic can help to understand the barriers faced by coaches, as well as provide evidence to guide future actions according to the coaches' working environment.

Given the scenario presented (social isolation, specific demands of coaches, and handball organization in Brazil), this study aims to analyze the impacts caused by the pandemic on the handball coach's work during and after the period of social isolation. More specifically, we sought to identify: a) how the isolation period is interfering with handball teams; b) how the interaction with the players has been carried out and what topics are addressed by the coaches; c) how the coaches are using this period for professional learning and which themes are chosen most; d) how the coaches project the return of activities.

\section{Material and Methods}

\section{Research design}

The study was designed as a cross-sectional ${ }^{21}$. Data were collected through a self-administered online questionnaire, including closed-ended and open-ended questions. The questionnaire was accessible in Portuguese in May of 2020. This study complied with the Declaration of Helsinki and was approved by the ethics committee from the School of Physical Education and Sport of Ribeirao Preto/University of Sao Paulo (CAAE: 39796814.8.0000.5659).

\section{Participants}

Coaches who participated in a group called "School of Handball Coaches" were invited to participate in this study. This group was created during the pandemic period, with one meeting per week to discuss topics of sports training in handball (such as teaching approaches and rules for teams U-12 and U-14), match analysis, and professional training. One of the main objectives of the group is to discuss daily matters of coaches from different regions of Brazil who coach teams from different sports contexts (such as schools, clubs, and associations). Eligibility criteria required respondents to be handball coaches, aged 18 years or older, involved in any environment of training in Brazil (school sport, clubs, amateur teams, and professional teams), coaching teams from U-8 to adult. The questionnaires with duplicate responses $(n=3)$, and/or with incomplete personal data $(n=2)$ and/ or from foreign coaches' $(n=2)$ were removed from the sample.

It is important to highlight that it is not possible to establish the number of handball coaches in the Brazilian context, as there is no system that unifies information from public and private initiatives in states and cities. The sample of this study is not representative from a national perspective, which makes it difficult to generalize some results, but it allows us to explain the dilemmas, expectations, and challenges for professional activities during this period (also experienced by other coaches).

The questionnaire has been sent to 155 coaches and was available for two weeks. Our analyses included data from 52 handball coaches $(33.5 \%$ of the total, who answered all the questions) from different competitive levels of Brazilian handball. Although the questionnaire had a higher rate of return than the $25 \%$ recommended by the literature 29 , we believe that adherence was low due to factors such as the time available for responses (two weeks) and the overload of online activities by 
the coaches. The main characteristics of the participants are shown in Table 1.

Table 1 - General characteristics of the coaches

\begin{tabular}{|c|c|}
\hline Characteristics & Values \\
\hline \multicolumn{2}{|l|}{ Academic education } \\
\hline $\begin{array}{l}\text { Full License in Physical Education* } \\
\text { Bachelor in Physical Education } \\
\text { License in Physical Education } \\
\text { Unfinished (in progress) }\end{array}$ & $\begin{array}{c}57.7 \% \\
28.8 \% \\
7.7 \% \\
5.8 \%\end{array}$ \\
\hline \multicolumn{2}{|l|}{ Coaches experience } \\
\hline $\begin{array}{l}<5 \text { years } \\
5-10 \text { years } \\
10-15 \text { years } \\
15-20 \text { years } \\
>20 \text { years }\end{array}$ & $\begin{array}{l}25.0 \% \\
25.0 \% \\
25.0 \% \\
13.5 \% \\
11.5 \%\end{array}$ \\
\hline \multicolumn{2}{|l|}{ Gender of coaches } \\
\hline $\begin{array}{l}\text { Female } \\
\text { Male }\end{array}$ & $\begin{array}{l}24.2 \% \\
75.8 \%\end{array}$ \\
\hline \multicolumn{2}{|l|}{ Gender of teams } \\
\hline $\begin{array}{l}\text { Female } \\
\text { Male } \\
\text { Both }\end{array}$ & $\begin{array}{l}19.2 \% \\
17.3 \% \\
63.5 \%\end{array}$ \\
\hline \multicolumn{2}{|c|}{ Number of teams coached by the coaches } \\
\hline $\begin{array}{l}\text { Minihandball (U-06; U-08) } \\
\text { U-10 } \\
\text { U-12 } \\
\text { U-14 } \\
\text { U-16 } \\
\text { U-18 } \\
\text { U-20/U-21 } \\
\text { Adults/High performance } \\
\text { College/Adults amateur }\end{array}$ & $\begin{array}{c}7 \\
18 \\
34 \\
40 \\
33 \\
24 \\
12 \\
12 \\
24\end{array}$ \\
\hline
\end{tabular}

The average age of the coaches was $37.3( \pm 8.5)$ years $(\min =21.1 ; \max =56.5)$, with a professional experience of 11.8 $( \pm 8.3)$ years $(\min =1 ; \max =34)$. The frequency of weekly contact between coaches and athletes was distributed as follows: $19.2 \%$ once a week, $26.9 \%$ twice a week, $36.6 \%$ three to four times a week, and $17.3 \%$ over four times a week. It was possible to observe heterogeneity in the coaches' profiles since in addition to age and time of professional experience, there were differences in the sports contexts in which they work (school, clubs, social projects, and city teams). This heterogeneity was considered positive by the researchers because it represents a general overview of the dilemmas inherent in different contexts (divided by age) of Brazilian handball.

\section{Data collection}

The questionnaire was designed to collect descriptive data and identify practices or opinions present in a specific population ${ }^{21}$. We identified the opinions of handball coaches on aspects inherent to interactions with their players and professional learning in social isolation due to a pandemic context (COVID-19), as well as expectations for the return of training sessions.

The questionnaire was created using Google Forms ${ }^{\circledR}$ tools and made available online in Portuguese, with open-ended and closed-ended questions. All 6 authors of this study (four researchers and two handball coaches) helped in the elaboration and adjustments of the questionnaire, to validate the content $\mathrm{t}^{22}$ and to give consistency to the final version by consensual agreement.

The online questionnaire was designed to collect information on:

1 - Coaches' demographics, including information about age, sex, and State;

2 - Characteristics of academic graduation and coaches' experiences, including academic education (Full License in PE, Bachelor in PE, License in PE, or unfinished - in progress), experience as a coach (years);

3 - Teams' characteristics, including sex, and athlete's age;

4 - Routine with the team in social isolation, to identify if the coaches were in contact with their athletes, the weekly frequency, the means used (WhatApp, Facebook, Zoom and/ or Google Meet, and others), the content addressed with the athletes, and how the coaches approach these contents. The contents were classified as technical (repetition of the technique, isolated from the game context, centered on 'how to do'), tactical (related to players' decision making, such as 'what', 'why' and 'when' to do, the team's game model, the tactical elements, offensive/defensive systems, and match analysis), physical fitness (referring to specific exercises which stimulate aerobic and anaerobic capacity, power, agility, and coordination) and psychological (involving motivation, union, emotional control among others);

5 - Routine for professional learning in social isolation, including how coaches are studying (lives on Instagram, watching handball games, online lectures, reading books, reading scientific articles, participating in virtual meetings with other professionals, and others), what content they are looking for and if they have difficulties in finding specific content. As it is a closed-ended question, the contents were grouped into teaching approaches (alluding to their concepts), performance evaluations (which included the assessment of technical, tactical, and fitness aspects), specific exercises (specific examples for handball, with the intention of increasing the repertoire of exercises, without referring to teaching approaches), team management (with mention of aspects such as leadership and people management), and others (open-ended question);

6 - Use of digital resources by the coach, to identify whether there is use and what resources are being used to produce or share content;

7 - Consequences from social isolation, divided into opportunities and barriers;

8 - Prospects for the period after social isolation (return to training).

Due to the participation of coaches with heterogeneous profiles, aspects related to new technologies (mainly) were considered by some coaches as barriers and by others as opportunities for career and team development. 


\section{Data analysis}

To close-ended questions, the comparisons for each quantitative variable (i.e. training content, resources used to contact athletes, resources, and content for professional learning) were performed by using descriptive analysis. For open-ended questions, Thematic Analysis ${ }^{23,24}$ was used to identify, analyze, and construct the themes. Thematic Analysis makes it possible to answer different research questions, whether in studies of personal perspectives ${ }^{23}$ or the sports context ${ }^{24}$, over six steps ${ }^{23}$ : a) familiarization with the data; b) coding; c) search for themes; d) review of the themes; e) naming of themes; f) report.

The choice for this method was due to its relevance in analyzes related to sport ${ }^{25}$, the possibility of summarizing large volumes of data, and its flexibility ${ }^{23,24}$. Through this analysis, it was possible to establish categories of answers that revealed the barriers and opportunities reported by handball coaches during social isolation and their expectations for after this period. In this sense, three researchers with previous experiences as handball players, coaches, and researchers (one with Ph.D. program concluded, one with master's program concluded, and one with the master program in progress) were involved in the process of identifying, defining, and analyzing the themes, based on a detailed, inductive analysis, at the latent level ${ }^{23,24}$.

The answers to the open-ended questions were analyzed according to the Reflexive Thematic Analysis method ${ }^{25}$. The analysis line-by-line ${ }^{26}$ allowed the creation of the following preliminary analytical categories: athletes' interpersonal relationship; athletes' game knowledge; personal development; athletes' performance; clubs and competitions situations; athletes' evasion; training routine of teams; team performance; familiarization of coaches with virtual environment tools; coaches' specific knowledge; relationships with athletes. After grouping, reviewing, and shaping the preliminary analytical categories, the following themes were produced: (a) pandemic influences for handball practice: present and future; (b) perspectives on coaches' professional learning.

\section{Results}

The study findings were grouped for a better interpretation of the data. The contents taught by the coaches to their teams, the contents sought for professional learning, the barriers and opportunities caused by the period of social isolation, and the future perspectives (post-pandemic period) were revealed through the closed-ended and open-ended questions.

The thematic map can be represented visually or in text form to reveal the facets of the thematic analysis development process and to identify the themes and sub-themes ${ }^{26}$, and in this study, the option was for textual representation. The first theme consists of the description of the main barriers and opportunities for the handball practice in the period of social isolation, as well as in the post-pandemic period. The second theme is related to the professional learning of handball coaches, with the mapping of the contents that they consider interesting and with the challenges and opportunities brought by the pandemic.
Pandemic influences for handball practice: present and future

When asked about training sessions (closed-ended questions), coaches reported their preference for using platforms such as Whatsapp (94.2\%) and Zoom/Google Meet (75.0\%), as they allow direct contact and instantly share information with groups of people. These resources allow calls with a large number of people, with access to the camera and audio in real-time (especially considering Zoom and/or Google Meet). The activities proposed by the coaches for the training sessions (online) mainly address content related to physical fitness (69.2\%), tactical aspects $(67.3 \%)$, and handball-related skills $(21.2 \%)$.

The qualitative data (open-ended questions) reported possible barriers imposed by the period of social isolation that is related to training sessions, athletes and coaches' performance, and the situation of clubs and competitions. These concerns extend to the post-social isolation period, mainly for reasons that can impact the training routine of the teams (such as the performance lost during this period and the interrupted development) as it is exposed next by Coach 9.

"The main loss has been in the annual planning progress and the
athletes'development. In some teams, we were at a critical point
for individual improvement and cohesion between players. The
sequence break may force us to remember some concepts [...].
Probably [the players] will suffer in relation to the aerobic and
anaerobic capacities, mainly related to specific physical fitness".

Another point in concern of the teams' routine is the possible drop out of the athletes and the interruption of the development process through sport. Coaches reported that the pandemic is negatively interfering in the team development, as mentioned by Coach 45: "the training sessions and matches would be essential to increase performance throughout the year, but we will try to meet the demands on player development in some way". The uncertainty for the return of competitions return is also an aspect that discourages athletes, as presented by Coach 35 ("I hope that this time will encourage them to come back and train well, but we know that many can leave") and can increase the evasion situation, as mentioned by Coach 3 ("as a school team, we still don't know how the return will be, I fear for the withdrawal of some students; there will also be a possible loss regarding the technique, but what worries me most is post-pandemic evasion").

The competitions are an important issue to the athletes' development, but the pandemic also brought a financial crisis that threatens the continuity of the activities of some teams, especially due to the difficulty in financing the main competitions:

Coach 3: "In my state, the main championships have been canceled. Most of my athletes are in the last year of the category and this would be a very important year for results that we may not have. We had a $50 \%$ decrease in funding for sports; the physical conditioning and motivation of the athletes to continue training also decreased, mainly because they know that they may not participate in the most important competitions in the state".

And finally, even in the face of all the adversities that coaches and athletes are experiencing, the opportunities presented 
by coaches revealed that there is future planning centered on adapting to the "new possible" scenario and will allow greater engagement of athletes in returning to activities (Coach 14: [I hope] "greater willingness and efforts to participate in activities"; and Coach 22: "perhaps we will have more empathy and experience activities more intensely”). The training sessions return is also seen as a possibility to athletes engage and appreciate the activities and will help to maintain the squads (Coach 9: "I believe that the meeting and the activities return after this forced breakdown will bring more appreciation and will give opportunities to set the teams"), but it is still seen with some uncertainty by the coaches.

\section{Perspectives on coaches' professional learning}

In the context of professional learning, coaches are engaging mainly in online lectures $(96.2 \%)$, virtual meetings $(92.3 \%)$ and lives on Instagram (90.4\%), which reveals various sources accessed through the virtual environment, whether by accessing recorded content or broadcast live. These events are usually coordinated by more experienced coaches (internationally renowned or consolidated at the national level) and/or by teachers who develop their work associated with specific topics (e.g. handball at school, physical fitness, and goalkeeper training). The content accessed by coaches for professional learning showed a greater emphasis on teaching approaches (82.7\%) and specific exercises $(75.0 \%)$, followed by specific aspects of each age group and sports management (63.5\% each). Such results reveal the coaches' concern to make the game more attractive to athletes, as they deepen their knowledge in teaching approaches and with greater possibilities of exercise variations throughout the training. Such aspects respond to the need to make the environment motivating and challenging when activities return after social isolation. Besides that, when coaches were asked if they had difficulty finding specific handball content in their searches, there were highlighted topics related to the teaching of technical-tactical specificities (e.g. goalkeeper training, teaching approaches, and match analysis) and the lack of specific didactic materials in Portuguese.

In order to analyze the coaches' professional learning, some coaches highlight that the new technologies seem to be an important barrier (Coach 3: [the pandemic] "made us rethink many things: we are studying more and learning tools that were not part of our daily lives"), which limits the possibilities of communication with their athletes. Although such barriers are a worrying scenario, some coaches mentioned that this period is also full of opportunities for reflection on interpersonal relationships, learning new tools, and expanding knowledge about handball, as mentioned by Coach 9 and Coach 20 below:

Coach 9: "I see maintaining the team's identity and mutual commitment as key elements in this period. Regarding the coexistence between athletes, reduced contact and temporary withdrawal tend to cool internal conflicts and, perhaps, increase interpersonal tolerance within the group".

Coach 20: "The use of social networks was common for communication between coaches and athletes, but as a tool for studies it had not yet been used. We are working to make this tool part of the training".

\section{Discussion}

This study aimed to identify the interferences of the period of social isolation due to the pandemic of COVID-19 in the professional activities of handball coaches, as well as to identify a possible scenario after the return of activities. The questionnaires revealed aspects related to team training sessions in social isolation (such as barriers and opportunities, relationships established by the coaches with their teams - content covered and resources used, and future perspectives), and to the professional learning of coaches (such as the resources used, the topics sought by the coaches, and the possible consequences of this period for the activities return).

\section{Pandemic influences for handball practice: present and future}

In the coaches' opinion, the specific practice of handball is suffering the impacts of the impossibility of continuing the training sessions, which reduces the players' motivation, decreases the physical conditioning and the specific technical-tactical development of the team's game model. These concerns about the physical fitness of the teams are based on the fact that long periods of breaks decrease the levels of different motor skills $^{27,28}$. Although coaches have been in contact with their players, especially for the prescription of physical training, the specificity (basic principle of sports training) of handball is not being considered. The coaches' concern with the losses caused by the absence of collective training is evidenced by mentioning the emphasis on tactical content and physical fitness. In soccer, a similar scenario was reported and coaches are working directing efforts to minimize performance losses ${ }^{15}$.

Although coaches mention the emphasis on aspects of physical conditioning and tactical knowledge of players, there is no guarantee that there will be a transfer to the context of the game due to its constraints (interactions between players) and its specificities, which reinforces the use of game-based approaches in the activities return ${ }^{16}$. However, the emphasis on these contents can also be linked to professional training, as coaches that do not take part in a formal learning process preferred technique approaches when compared to those who are undergraduate ${ }^{29}$.

Regarding psychological aspects, the coaches pointed out that some athletes are unmotivated by the uncertainty of participation in championships, especially due to the decrease in financial support by the entities and the impossibility of organizing collective activities and sports events. To solve these problems, interviewed coaches mentioned that the activities emphasized in the training sessions during the social isolation are strengthening the players' interpersonal relationships (such as unity, trust, respect, and tolerance). These findings cannot be generalized, mainly because 
there are teams in which players do not even have access to the internet. The emphasis on these aspects has been suggested as a way to face and minimize the negative effects of social isolation', which was confirmed in the results of this study.

Another difficulty pointed out by the coaches refers to the adaptations of the exercises and training, as well as the relationship with the athletes during social isolation. According to this situation, coaches adopted match analysis as a routine for teams and the teaching of theoretical content as opportunities during this period. Teaching through a 'theoretical way' and match analysis were proposed by the team's coach, mainly because in Brazil handball teams do not regularly have a full coaching staff. These analyses basically focused on recorded games of the own team, of opposing teams, and of the main clubs/national teams, however, it was not possible to quantify the time dedicated specifically to these activities in the weekly schedule. The use of match analysis can be a solution to the demands presented by social isolation as it stimulates players' tactical awareness, gives them feedback about their decisions in the game, and explores theoretical content in training sessions $^{30,31}$. Therefore, these actions could minimize the distance between players, adopt new routines for the teams, and increase the specific technical-tactical knowledge about the game ${ }^{4,32}$.

The relevance of projecting activities from the analysis of possible barriers and opportunities was highlighted by the coaches. In this sense, it is possible to prepare a plan for the moment when the collective training returns. The analysis of the answers about the return of the training showed concern with the hygiene of the athletes, the decrease of the physical fitness and technical-tactical performance of the athletes, and the professional learning of the coaches. The decrease in athletic performance caused by training stoppage has been observed in other sports and, when combined with changes in living habits due to the pandemic, cause uncertainty about competitions ${ }^{15}$. Participation in competitions (organized by adults) is an important element for the development of youth players ${ }^{33}$. As it is seen in our findings, the competition interruptions can compromise the athletes' motivation, can cause dropouts and difficulties in the maintenance of sports practice. To minimize these problems, it is suggested that the competitions organized by the entities include adaptations in their regulations, leading it to a more inclusive and diversified environment (especially with flexibility in age groups, the number of game periods, and the length of each period), and in the reduction of costs for participation due to the financial difficulties arising from this period.

The coaches also reported some positive projections after the social isolation period. Such projections stipulated for the return of activities refer to the improvement of interpersonal relationships and motivation for training sessions (due to the withdrawal of teammates and activities with the team). When the coaches referred more specifically to the training, it was possible to note that the activities proposed during social isolation can also be inserted in the context of the team when activities on the court are allowed. Exchanging experiences between coaches and athletes during this period could provide knowledge about the needs of athletes that could support feedback and questions in a more specific way in training ${ }^{34-36}$. Therefore, it is expected that observation and reflection on the players' technical-tactical knowledge could provide more precise interventions during training sessions. According to the expectations mentioned by the coaches for the return of training session, it is suggested to adopt principles of the game based approaches, since these approaches aim to stimulate the experiences in contextualized situations and critical thinking about the specifics of the sport ${ }^{37}$.

\section{Perspectives on coaches' professional learning}

The challenge of using resources based on information and communication technology for teaching was identified in this study as a barrier and as an opportunity faced by some coaches during social isolation. These themes have been discussed and difficulties have also been reported for higher education athletes ${ }^{38}$, but it is understood that this is an efficient resource to overcome the difficulties brought particularly by this period, whereas the imposed situation did not provide enough time to plan and adapt to the needs ${ }^{4}$. Although configured as a challenge for teachers ${ }^{38}$, these resources have been used by other professionals in the field of Physical Education to teach classes and training ${ }^{9}$ and were also reported by coaches of this study. Among the technological resources available, the most used by coaches were WhatsApp, Google Meet, and/or Zoom. Possibly, these resources were used more because they allow the sending and sharing of information instantly, in addition to providing contact by video and voice in real-time, allowing interaction between the coaches and athletes and corrections of movements. Due to the difficulties mentioned by the coaches, it would be interesting to search for ways to better understand each resource management through online tutorials or by exchanging experiences with other coaches, for example.

The findings also revealed that online lectures, virtual meetings, and lives on Instagram have been used for coaches to build their professional knowledge and prepare for the return to activities. Teaching approaches and handball exercises were the most searched content on the internet, whose search may have been influenced by the need to propose alternatives for training sessions after social isolation. This can be an alternative found by coaches to change training stimuli, promote a challenging environment for players, and show that this period dedicated to studies was also used for innovations. If, on the one hand, coaches have reported that the use of blogs expands the ambiguity of content and limits collaboration and engagement between them ${ }^{39}$, participation by the coaches of our study in open online meetings seems to avoid this redundancy. In addition, this format allows the discussion of topics by coaches from different contexts (school, clubs, city teams...) and contributes to the production of new questions relevant to specific professional performance. From this perspective, coaches can easily access other coaches from different regions of the country and obtain valuable information for their professional learning, which are the main criticisms of formal qualification programs ${ }^{40}$. This possibility values social interactions, as verified by Stoszkowski and Collins ${ }^{41}$, and highlights the importance of participation in groups such as the "School of Handball Coaches" (with characteristics that resemble a community of practice). 
Social distance has brought a need for distance learning, and with this, coaches have sought improvement through online courses/lectures and lives on Instagram. This fact represents that, due to the pandemic situation, coaches are participating in unconventional learning situations for them ${ }^{19,42}$, which also justify the presented difficulties by some coaches for this resources use. On the other hand, despite the limitations in distance learning, participation in virtual meetings supported an interesting strategy in the period of social isolation ${ }^{4}$ and corroborate the preference of other coaches for professional development, as they reported that the non-mediated are the most sought learning situation ${ }^{19,20,41,42}$. While the most non-mediate learning sources for the coaches' practice were more valued by them ${ }^{41}$, in our study these demands were also shown to be emerging and important for the dissemination of specific content by coaches from different contexts. However, due to the exception caused by the pandemic, the application of the concepts learned will occur in the future, still in an uncertain way, which justifies some benefits pointed out by the coaches (mention benefits).

The findings revealed that a topic to be addressed in courses for coaches is the use of technological resources since they reported difficulties in applying them in training and accessing information. In a review study, Cushion and Townsend ${ }^{18}$ pointed out that the difficulties found by coaches on time management are not exclusive to this period and, therefore, greater attention was also suggested for this content during coaches' education. In this sense, if the use of technology content had more attention, this can improve their training planning and professional enhancement, such as helping with time management ${ }^{18}$. Therefore, it is suggested an alignment in the coaches' education courses to ensure that their professional environment needs are being developed with them, as it is known that the learning process has a great impact on coaches' work ${ }^{29}$.

The analysis of the results revealed that although the coaches have access to many contents, with different teachers and/ or coaches, and with free access, it is not possible to know if this knowledge will be applied in the training of the teams, as discussed by Glang et al. ${ }^{43}$. A possible suggestion for the context of the coaches in our study is the engagement in mentoring programs to generate reflective practices about the contents, the training philosophy, the application of concepts for solving team problems, and the elaboration/presentation of specific materials (e.g. training diaries). In a complementary way, the several opportunities for simultaneous activities provoke the choice according to the coach's professional practice, and there is not always a plan about what they want to learn, in addition to eventual fatigue through electronic devices. In this sense, the creation of an entity by handball coaches could also provide support for the use of different technological resources and for specific learning, which is close to the professional field and develops contextualized actions.

In summary, this study revealed the preference for using platforms that allow the sharing of information individually or in a group during the isolation social. These platforms are used to emphasize physical fitness and tactical content. For professional learning, handball coaches are looking for issues such as teaching approaches and specific handball exercises during social isolation. Coaches also mentioned the concern about maintaining the athletes' physical and technical-tactical performance during the period of social isolation, as well as the uncertainties for the future and the difficulties with the use of unconventional resources for training the teams. Finally, coaches reported difficulties in applying them in training and accessing information, and we suggested that the courses for coaches emphasize aspects that enable the learning of new technologies. The uncertainties reported by the coaches culminate in the need to adopt a "new normal" considering several factors for risk mitigation ${ }^{44}$, which is likely to cause changes and challenges for the training of the teams.

The findings of this study can assist in the production of interesting content for coaches and contribute to maintaining and/or improving the performance of athletes and teams, since the pandemic required taking quick actions by coaches for teams or professional learning, without prior planning.

\section{References}

1. Ganem F, Mendes FM, Oliveira SB, Porto VBG, Araujo W, Nakaya $\mathrm{H}$, et al. The impact of early social distancing at COVID-19 Outbreak in the largest Metropolitan Area of Brazil. medRxiv. 2020.

2. Williams S, Armitage C, Tampe T, Dienes K. Public perceptions and experiences of social distancing and social isolation during the COVID-19 pandemic: A UK-based focus group study. BMJ Open. 2020;10:e039334.

3. Organization WH. Director-General's statement on IHR Emergency Committee on Novel Coronavirus (2019nCoV). https:/www.who.int/dg/speeches/detail/who-director-general-s-statement-on-ihr-emergency-committee-on-novel-coronavirus-(2019-ncov)2020 [Accessed 2nd June 2020].

4. Crawford J, Butler-Henderson K, Rudolph J, Glowatz M. COVID-19: 20 Countries' Higher Education Intra-Period Digital Pedagogy Responses. J. Appl. Teach. Learn. 2020;3(1):1-20.

5. Brazil. Painel Coronavírus https://covid.saude.gov.br/: Brazilian Ministry of Health; 2020. [Accessed 2nd July 2020].

6. Candido D, Claro IM, Jesus JG, Souza WM, Moreira FRR, Dellicour $\mathrm{S}$ et al. Evolution and epidemic spread of SARS-CoV-2 in Brazil. Science. 2020;369(6508):1255-1260.

7. Decree 64.879/March 20, 2020. Recognizes the state of public calamity, resulting from the COVID-19 pandemic, which affects the State of São Paulo, and takes related measures.[Decreto 64.879, de 20 de Março de 2020. Reconhece o estado de calamidade pública, decorrente da pandemia do COVID-19, que atinge o Estado de São Paulo, e dá providências correlatas]. (2020). https://www. al.sp.gov.br/norma/193347 [Accessed 3rd June 2020].

8. Oliveira SB, Porto VBG, Ganem F, Mendes, FM, Almiron M, Oliveira WK et al. Monitoring social distancing and SARS-CoV-2 transmission in Brazil using cell phone mobility data. medRxiv. 2020;2020.04.30.20082172.

9. Matias T, Dominski FH, Marks DF. Human needs in COVID-19 isolation. J. Health Psych. 2020;25(7):871-82.

10. Wahl-Alexander Z, Sinelnikov O. Using Physical Activity for Emotional Recovery After a Natural Disaster. JOPERD. 2013;84(4):23-8. 
11. Jones RL, Thomas GL. Coaching as 'scaffolded' practice: further insights into sport pedagogy. Sports Coach Rev. 2015;4(2):65-79.

12. Bowes I, Jones RL. Working at the Edge of Chaos: Understanding Coaching as a Complex, Interpersonal System. Sports Psychologist. 2006;20(2):235-45.

13. Hay P, Dickens S, Crudgington B, Engstrom C. Exploring the Potential of Assessment Efficacy in Sports Coaching. Int. J. Sport Sci. Coach. 2012;7(2):187-98.

14. Chen P, Mao L, Nassis GP, Harmer P, Ainsworth BE, Li F. Wuhan coronavirus (2019-nCoV): The need to maintain regular physical activity while taking precautions. J. Sports Health Sci. 2020;9(2):103-4.

15. Azevedo AM, Petiot GH, Clemente FM, Nakamura FY, Aquino R. Home training recommendations for soccer players during the

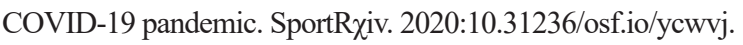

16. Kinnerk P, Harvey S, MacDonncha C, Lyons M. A review of the game-based approaches to coaching literature in competitive team sport settings. Quest. 2018;70(4):401-18.

17. Menezes R, Ramos N, Marques R, Nunomura M. Teaching handball to U-16 and U-18 women's teams: coaches' perspective in the long-term. Motriz: J. Phys. Ed. 2018;24(4):e101838.

18. Cushion $\mathrm{C}$, Townsend $\mathrm{R}$. Technology-enhanced learning in coaching: a review of the literature. Ed. Rev. 2019;71(5):631-49.

19. Menezes RP, Modolo F, Santos WR, Musa VdS. Influence of normative institutions of handball for coaches' learning: the standpoint of Sao Paulo State coaches. E-Balonmano.com: Revista Ciências Dep. 2017;13(3):183-90.

20. Musa VdS, Modolo F, Barreira CPdS, Tsuji GH, Menezes RP. Representações dos treinadores sobre o papel das instituições reguladoras do handebol para sua formação. Rev. Port. Ciência Desp. 2017;Supl.1:298-306.

21. Thomas J, Nelson J, Silverman S. Research methods in physical activity. 7th ed. Champaign, IL, Human Kinetics; 2015.

22. Dillman A. Mail and internet surveys: the tailored design method. New York, John Wiley \& Sons; 2000.

23. Braun V, Clarke V. Using thematic analysis in psychology. Qual. Res. Psych. 2006;3(2):77-101.

24. Braun V, Clarke V, Terry G. Thematic analysis. Qual. Res. Clin. Health Psych. 2014;24(1):95-114.

25. Braun V, Clarke V. Reflecting on reflexive thematic analysis. Qual. Res. Sports. Exer. Health. 2019;11:1-9.

26. Braun V, Clarke V. Thematic analysis. In: Glisczinski D, editor. APA handbook of research methods in psychology 2: American Psychological Association; 2012. p. 57-71.

27. Guimarães-Ferreira L, Bocalini D. Detraining attenuation during the COVID-19 pandemic: practical considerations for home-based strength and power training. Rev. Bras. Fisiol. Exerc. 2020;19:S47-S55.

28. Shavandi N, Talebian S, Aslanpoor S, Sheikhhoseini R, Zeinali S. The effects of strength training and combination technique on preserving the strength of plantar flexor muscles after a period of detraining. The J. Sports Med. Phys. Fit. 2016;56(9):990-6.

29. Stodter A, Cushion C. Evidencing the impact of coaches' learning: changes in coaching knowledge and practice over time. J. Sports Sci. 2019;37(18):2086-93.

30. O'Donoghue P. The use of feedback videos in sport. Int. J. Perform. Anal. Sports 2006;6(2):1-14.

31. Wiemeyer J. Learning with multimedia-concepts and experiences. Int. J. Perform. Anal. Sports. 2001;1(1):37-51.
32. Pityn M, Bohuslavska V, Khimenes K, Neroda N, Edeliev O. Paradigm of theoretical preparation in sports. J. Phys. Ed. Sport. 2019;19(6):2246-51.

33. Côté J, Erickson K, Abernethy B. Play and practice during childhood. In: Côté J, Lidor R, editors. Conditions of children's talent development in sport. Morgantown, WV: Fitness Information Technol. 2013.p. 9-20.

34. Fairhurst KE, Bloom GA, Harvey WJ. The learning and mentoring experiences of Paralympic coaches. Disab. Health J. 2017;10(2):240-6.

35. Greenberg EC, D M. How parkour coaches learn to coach: coaches' sources of learning in an unregulated sport. J. Advent. Ed. Outdoor Learn. 2020;20(1):15-29.

36. Rivas-Borbón OMV-U, F, Revuelta-Sánchez I, Salas-Cabrera J, Gutiérrez-Vargas JC. La formación y adquisición de conocimiento para entrenar y dirigir de los entrenadores del fútbol élite de Costa Rica. MHSalud. 2018;5(2):3-19.

37. Light R, Evans J. Positive pedagogy for sports coaching. Sport Ed. Soc. 2017;22(2):1-17.

38. Denysova L, Shynkaruk O, Usychenko V. Cloud technologies in distance learning of specialists in physical culture and sports. J. Phys. Ed. Sport 2018;18(1):469-72.

39. Stoszkowski J, Collins D, Olsson C. Using shared online blogs to structure and support informal coach learning. Part 2: the participants' views and implications for coach education. Sport Educ. Soc. 2015;22(3):407-25.

40. Nelson L, Cushion CJ, Potrac P. Formal, nonformal, and informal coach learning: a holistic conceptualization. Int. J. Sport Sci. Coach. 2006;1(3):247-59.

41. Stoszkowski J, Collins D. Sources, topics and use of knowledge by coaches. J. Sport Sci. 2016;34(9):794-802.

42. Mesquita IR, J, Santos S, Morgan K. Coach learning and coach education: Portuguese expert coaches' perspective. Sport Psych. 2014;28(2):124-36.

43. Glang A, Koester M, Beaver S, Clay J, McLaughlin K. Online Training in Sports Concussion for Youth Sports Coaches. Int. J. Sport Sci. Coach. 2010;5(1):1-11.

44. Organization WH. Calibrating long-term non-pharmaceutical interventions for COVID-19 https://apps.who.int/iris/bitstream/handle/10665/332099/WPR-DSE-2020-018-eng.pdf?sequence=1\&isAllowed=y2020. [Accessed 2nd July 2020].

\section{Corresponding author}

Rafael Pombo Menezes

University of Sao Paulo (USP). School of Physical Education and Sport of Ribeirao Preto (EEFERP). Ave Bandeirantes, 3900 - Campus USP - 14040-907 - Ribeirao Preto, SP, Brazil

Telephone: +55 16 3315-0349

Email: rafaelpombo@usp.br

Manuscript received on June 22, 2020

Manuscript accepted on September 14, 2020

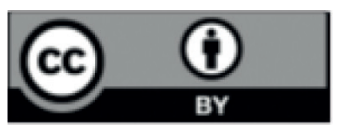

Motriz. The Journal of Physical Education. UNESP. Rio Claro, SP, Brazil - eISSN: 1980-6574 - under a license Creative Commons - Version 4.0 